\title{
Asymmetric effect of structural change and renewable energy consumption on carbon emissions: designing an SDG framework for Turkey
}

\author{
Tomiwa Sunday Adebayo ${ }^{1}$ (D) . Seun Damola Oladipupo ${ }^{2} \cdot$ Husam Rjoub $^{3}$. \\ Dervis Kirikkaleli ${ }^{4}$ (D) Ibrahim Adeshola ${ }^{5}$
}

Received: 25 August 2021 / Accepted: 14 December 2021 / Published online: 4 January 2022

(C) The Author(s), under exclusive licence to Springer Nature B.V. 2021

\begin{abstract}
A plethora of studies have shown that structural change helps nations achieve socioeconomic growth. The influence of structural change on environmental quality, on the other hand, has yet to be thoroughly investigated. As a result, the current study assesses the asymmetric impact of structural change on $\mathrm{CO}_{2}$ emissions while controlling for the effects of economic progress, renewable energy utilization, and nonrenewable energy in Turkey. To this end, this research used yearly data stretching from 1965 to 2019. The study applied several econometric approaches including nonlinear auto-regressive distributed lag (NARDL) and spectral causality to assess these associations. The outcomes from the NARDL reveal that variations in the regressors have a nonlinear influence on $\mathrm{CO}_{2}$ in Turkey. Moreover, the transition in the economy's structure helps to boost ecological quality, while the findings also show that Turkey's current economic progress trajectory is unsustainable due to the country's reliance on fossil fuel-based energy consumption. The outcomes of the spectral causality test also show that structural change can predict $\mathrm{CO}_{2}$ emissions in Turkey at different frequencies. Based on the study findings, the government should encourage investment in the service sector in order to maintain a suitable level of environmental sustainability.
\end{abstract}




\section{Graphical abstract}

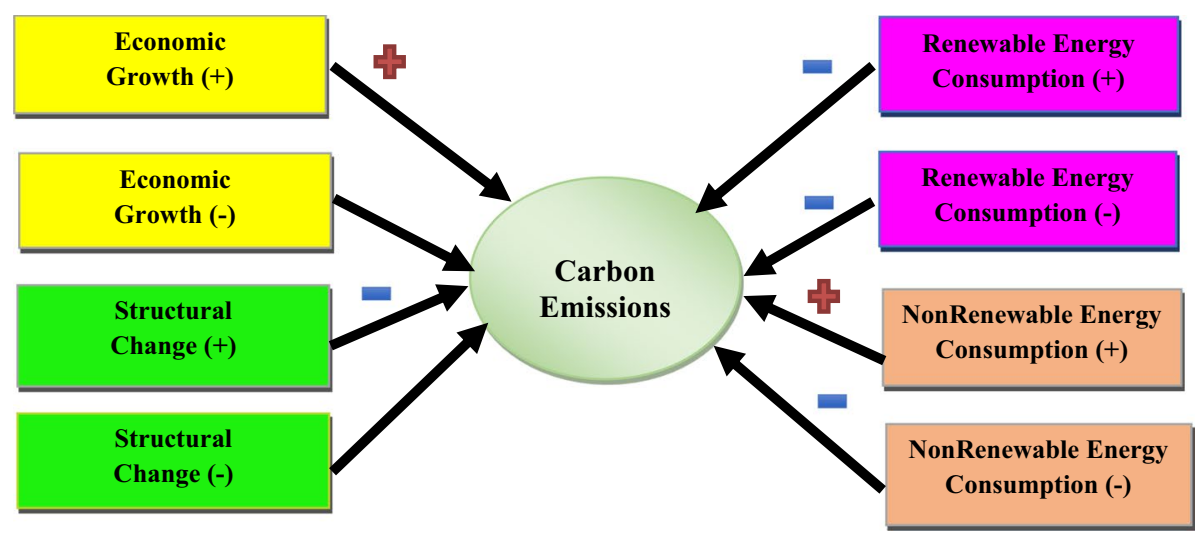

Keywords Structural change · Economic growth - Carbon emissions · Renewable energy · Turkey

\section{Abbreviations}

$\begin{array}{ll}\text { ADF } & \text { Augmented Dickey Fuller } \\ \text { FMOLS } & \text { Fully Modified Ordinary Least Square } \\ \text { NARDL } & \text { Nonlinear ARDL } \\ \text { ZA } & \text { Zivot and Andrews } \\ \text { PP } & \text { Phillip Perron } \\ \text { DOLS } & \text { Dynamic Ordinary Least Square } \\ \mathrm{CO}_{2} & \text { Carbon Emission } \\ \text { ARDL } & \text { Auto-Regressive Distributed Lag } \\ \text { SVD } & \text { Structural Change } \\ \text { NREN } & \text { Nonrenewable Energy Consumption } \\ \text { REN } & \text { Renewable Energy Consumption } \\ \text { SCT } & \text { Spectral Causality } \\ \text { GDP } & \text { Economic Growth } \\ \text { DUM } & \text { Dummy }\end{array}$

\section{Introduction}

When a country attempts to accomplish economic growth, it must depend on its pool of resources, which comprises both intellectual and natural resources (Adebayo \& Kirikkaleli, 2021). During the initial phase of economic expansion, a country's economy is based on its stock of natural resources, which are easy to use and consume. Natural resource use aids in the development of nations, although this consumption trajectory degrades the ecological quality of these nations (Alola et al., 2021; Su et al., 2021). Constant exploitation of natural resources causes damage to the environment, and it is at this point that countries turn to their intellectual resources in search of alternative energy sources. Nevertheless, because of the high costs of implementation, it might not always be viable for countries to incorporate 


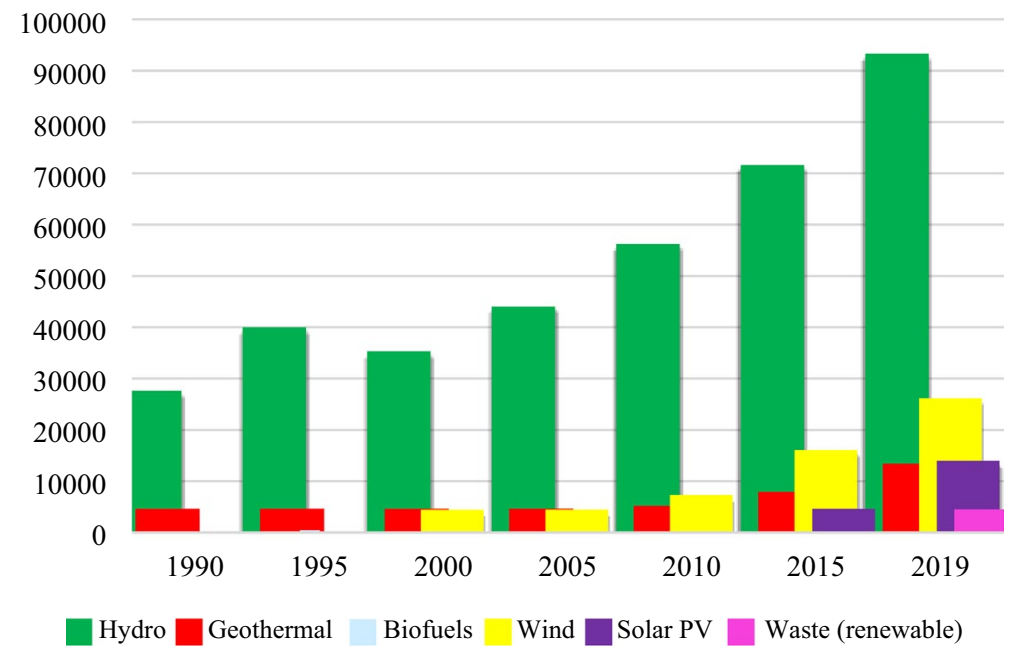

Fig. 1 Low-carbon electricity generation by source (Gwh) Source: (IEA, 2021)

alternative energy sources, as the cost of implementation might have an impact on the trajectory of economic expansion. As a result, in order to promote industrialization, fossil fuel usage is mostly used by countries for the generation of energy. The country's biocapacity is impeded as a result of degradation of the environment triggered by the utilization of fossil fuel-based alternatives, since the country's absorptive capability of water, air and land may not be adequate to absorb the waste created in the process of economic expansion (Agyekum et al., 2021; Yuping et al., 2021). In such situations, it is important to note that developing economies are more inclined to support fossil fuel-based solutions over alternative energy options, as achieving economic goals is more important to these countries than maintaining environmental quality. Turkey is a country with such distinctive characteristics. As highlighted by Kirikkaleli et al. (2021), Turkey's current economic progress trajectory is impeding the achievement of SDG 13 (high ambient GHG emissions), SDG 14 (poor Black Sea environment protection), and SDG 15 (poor land quality fortification). Because of its growth trend, meeting the targets of these SDGs has proven to be a challenge for Turkey. To address this issue, governments are working to minimize their reliance on fossil fuels by identifying and developing alternative renewable energy sources.

Despite the fact that Turkey has achieved significant progress in terms of the generation of renewable energy since 2009, renewable energy (REN) is still used considerably less than nonrenewable energy (NREN). In 2018, REN accounted for roughly 32\% of Turkey's overall electricity generation. Hydropower accounts for the majority of Turkey's REN portfolio (see Fig. 1). Turkey has a competitive edge in terms of the generation of renewable energy due to its geographic position (i.e., wind, solar). As a result, it possesses the ability to transform environmental challenges into opportunities. Nonetheless, Turkey's inefficient educational system may prove to be an obstacle to renewable energy deployment. The failure of policymakers in Turkey to achieve the SDG 9 objectives (insufficient patents and R and D) and SDG 4 (poor academic outcomes in science) is a manifestation of this situation (Akadırı et al., 2021). As a result, while economic expansion driven by fossil fuels is eroding ecological quality by increasing the ecological footprint, the full potential of renewable energy generation has yet to be achieved. 
The current analysis is based on the well-known "Limits to Growth" concept, which states that nations' natural resource-driven economic progress patterns are unsustainable and restricted (Meadows et al., 1974). Persistent reliance on fossil fuel energy sources may provide Turkey with short-term economic gains, but it may be unsustainable in the long run. Although Turkey is one of the 197 parties to the 2015 Paris Climate Pact 2015, they are one of the ten countries that have yet to sign the agreement (Kirikkaleli \& Kalmaz, 2020). Several topics relating to the challenges of climate change in Turkey were raised at the 2019 COP21 Barcelona Convention (Sharif et al., 2020). Some of the causes of these problems highlighted included legislative barriers as well as an inability to disseminate ideas across the country.

It is important to analyze the influence of various types of energy usage on the quality of the environment in a nation plagued by challenges in achieving sustainable development. Even though it is clear that using renewable energy can assist with improving the quality of the environment, the country may not be able to adopt it since it might disrupt its economic expansion trajectory. Furthermore, the country's social environment may not be ready to support the widespread adoption of alternative energy technologies across the country. As a result, the influence of renewable energy solutions on the quality of environment might fall short of expectations, as socioeconomic constraints may obstruct the implementation of these alternatives (Acheampong et al., 2019). In this case, the country would have to depend on current fossil fuel-based energy supplies, which will result in a steady degradation of the quality of the environment.

Moreover, structural change can also play a vital role in the mitigation of $\mathrm{CO}_{2}$. In this sense, most nations are transitioning from a more energy-intensive secondary industry to a more revenue-generating services sector. As a result, examining the transition from a highly industrialized sector to service sector-driven business may be a probable reason for the shift in an economy's structure. Although there are different definitions for changes in an economy's structure in the literature, the most significant is a long-term and continuous movement of the economy's share in these sectors (Luukkanen et al., 2015). The importance of structural transformation is that it allows a nation's economy to transition from low-polluting agriculture to a high-polluting secondary industry, and then back to a lower-polluting tertiary sector. As agriculture intensifies and industrialization accelerates, resource exploitation will escalate. Because of the proportional significance of the various sectors, shifting to information-based services and businesses can help to reduce world $\mathrm{CO}_{2}$ emissions. Changes in the institutional framework as well as the location of economic activity might also help these nations reduce environmental damage.

The goal of the structural change (SVD) is focused on emerging nations, because their domestic economies are shifting away from agricultural and primary sectors toward manufacturing and service. This strategy entails the deployment of efficient and innovative technologies that reduce the utilization of fossil fuels and stimulate the use of renewable energy sources. Significant advances in resource usage, international trade, socioeconomic circumstances consumption, and the economy's production process are frequently attributed to structural changes. In line with the research of Ali et al. (2020) in Pakistan, which was the first empirical study to scrutinize the effect of structural change and economic expansion on $\mathrm{CO}_{2}$, the current work takes a step further by assessing the influence of SVD and REN on $\mathrm{CO}_{2}$ while controlling for the effects of GDP and NREN in Turkey from 1965 to 2019. It is also essential to investigate the impact of energy utilization on the degradation of the environment, since the transition from a high-energy-consuming industrial sector to a low-energy-consuming sector might result in a reduction in energy utilization in the manufacturing process. While this is true, it is also important to realize that different degrees of 
income, as well as NREN and REN, may not have the same influence on $\mathrm{CO}_{2}$ emissions. In addition, this interrelationship must be examined in the long and short term, as the outcomes of the paper will be utilized to make policy decisions.

This current paper contributes to the body of knowledge in the following ways: Firstly, unlike previous empirical research that focused on structural transformation via the secondary sector and ecological sustainability, this research utilizes the value-added of the service sector as a metric of structural transformation for the case of Turkey. As a result, it is necessary to verify the impact of this sector on $\mathrm{CO}_{2}$. (ii) Relying on strong econometric methods is crucial for building a competent environmental strategy in an emerging nation like Turkey. Thus, this research applied NARDL developed by Shin et al. (2014) to investigate the association between $\mathrm{CO}_{2}$ and the regressors to offer a new perspective for policy recommendation. This approach can detect the various impacts of model parameters on the target policy variable in the event of favorable and unfavorable shifts. As a result, this method can be utilized to augment the research's policy-level contributions, demonstrating the research's analytical value. Lastly, we applied the spectral causality test (SCT) to detect the causal interrelationship between $\mathrm{CO}_{2}$ and REN, NREN, SVD and GDP. The innovation of the SCT is that it can capture causal interrelationships between variables at various frequencies (i.e., short and long term).

The subsequent section presents a synopsis of related studies, which is followed by the theoretical framework in Sect. 3. The data and methods utilized in this research are presented in Sect. 4. The study findings and conclusion are presented in Sects. 5 and 6, respectively.

\section{Synopsis of related studies}

This part of the research displays significant prior studies conducted on the influence of economic expansion (GDP), structural change (SVD), nonrenewable energy utilization (NREN) and renewable energy usage (REN) on carbon emissions $\left(\mathrm{CO}_{2}\right)$. The research divides the literature portion into distinct parts including the effect of each explanatory variable (GDP, SVD, NREN and REN) on $\mathrm{CO}_{2}$ emissions by applying various econometric methods, either time series or panel, for coherence of the literature review.

\subsection{Economic growth influence on $\mathrm{CO}_{2}$}

The interrelation between economic expansion (GDP) and carbon emissions $\left(\mathrm{CO}_{2}\right)$ is expansively discussed in energy and environmental economics. Nonetheless, researchers have produced mixed empirical outcomes. For instance, utilizing highly decentralized nations and the CS-ARDL method, Shan et al. (2021) scrutinized the $\mathrm{CO}_{2}$-GDP interrelationship utilizing data from 1990 to 2017. Their empirical outcomes revealed a positive $\mathrm{CO}_{2}$-GDP positive. In addition, the panel causality showed that GDP has predictive power on $\mathrm{CO}_{2}$. Similarly, Zhang et al. (2021) assessed the growth-emission nexus in Malaysia utilizing the novel wavelet and ARDL approaches between 1970 and 2018. The research outcomes showed that an upsurge in GDP contributes to emissions in Malaysia. Furthermore, their study uncovered a unidirectional causation from GDP to $\mathrm{CO}_{2}$. Likewise, In Turkey, the research of Kirikkaleli et al. (2021) on the emission-growth nexus used dual gap and FMOLS approaches from 1980 to 2016 and the study outcomes showed that GDP triggers emission levels positively in the country. Moreover, Odugbesan et al. (2021) investigated 
the growth-emissions association in Thailand utilizing a dataset between 1971 and 2016 and found that an upsurge in growth impacts $\mathrm{CO}_{2}$ positively, while they also found evidence of a one-way causation from GDP to $\mathrm{CO}_{2}$, indicating that GDP can predict $\mathrm{CO}_{2}$. The research of Yuping et al. (2021) in Argentina on the $\mathrm{CO}_{2}-\mathrm{GDP}$ interrelationship for the period from 1980-2018 supported the outcomes of the studies conducted by Kirikkaleli et al. (2021) and Shan et al. (2021) by establishing a negative GDP- $\mathrm{CO}_{2}$ interrelationship. Furthermore, the research of Su et al. (2021) in Brazil on the growth-emissions connection used quarterly data from 1984 to 2018 and determined that an increase in the emission levels in Brazil was caused by an upsurge in GDP. Moreover, the research of Farooq et al. (2019), Fatima et al. (2021), Shahzad (2020), and Bashir et al. (2021) also reported a positive growth-emissions relationship.

Contrarily, some studies on the association between GDP and $\mathrm{CO}_{2}$ have found a negative growth-emissions interconnection. For example, Rjoub et al. (2021) scrutinized the growth-emission nexus utilizing Sweden as a case study. The authors utilized the novel QQR approach to assess this association and their outcomes revealed that an upsurge in GDP mitigates $\mathrm{CO}_{2}$ in Sweden. Similarly, using USA as a case study, Usman et al. (2020) assessed the GDP-CO $\mathrm{CO}_{2}$ association utilizing a dataset from 1985Q1 to 2014Q4. The investigators utilized ARDL and their outcomes showed that a GDP upsurge abates $\mathrm{CO}_{2}$, while the VECM revealed evidence of a two-way causality between GDP and $\mathrm{CO}_{2}$. Likewise, the research of Sarkodie and Adams (2018) on the emissions-growth nexus in the USA, Australia, and China reported that GDP mitigates $\mathrm{CO}_{2}$ in the USA, while in China and Ghana, GDP contributes to the degradation of the environment.

\subsection{Renewable energy and nonrenewable consumption influence on $\mathrm{CO}_{2}$ Emissions}

A significant number of studies have been conducted on the effect of energy utilization (renewable and nonrenewable) on $\mathrm{CO}_{2}$. For example, the research of Kirikkaleli and Adebayo (2020) utilizing the global economy and a dataset from 1965 to 2018 assessed the NREN-REN-CO $\mathrm{CO}_{2}$ interrelationship. The investigators utilized spectral causality and FMOLS approaches and their outcomes revealed that nonrenewable energy impacts $\mathrm{CO}_{2}$ positively, while renewable energy impacts $\mathrm{CO}_{2}$ negatively. Also, the study of Tufail et al. (2021) using panel data from 1990 to 2016 and CS-ARDL disclosed a positive NREN-CO and negative REN-CO $\mathrm{CO}_{2}$ interconnection. Using a dataset from 1980 to 2016, Pata (2021a) examined the NREN-REN-CO $\mathrm{CO}_{2}$ nexus in the USA using the ARDL approach. The study outcomes showed that EC impacts $\mathrm{CO}_{2}$ positively, while REN contributes to the mitigation of $\mathrm{CO}_{2}$ in the USA. Likewise, the research of Adedoyin et al. (2021) utilized a panel dataset and recent econometric techniques and showed that the effect of $\mathrm{EC}$ on $\mathrm{CO}_{2}$ was positive, while the impact of REN on $\mathrm{CO}_{2}$ was negative. Moreover, Cheng et al. (2021) reported that REN decreased the emission levels in Belt and Road Initiative countries, while NREN increased emission levels. Mahalik et al. (2021) scrutinized the influence of energy on the emission levels of the BRICS nations from 1990 to 2015. The investigators utilized GMM and their empirical results revealed that the effect of NREN on $\mathrm{CO}_{2}$ was positive, while REN contributed to the sustainability of the environment. Moreover, the research of Fu et al. (2021) in selected African countries on the determinants of $\mathrm{CO}_{2}$ using a dataset from 1980 to 2014 and the ARDL approach found that the effect of $\mathrm{NREN}$ on $\mathrm{CO}_{2}$ was positive, while the impact of REN on $\mathrm{CO}_{2}$ was negative. Similarly, Cevik et al. (2021) scrutinized the energy use- $\mathrm{CO}_{2}$ relationship in the USA utilizing Markov-Switching VAR from 1980 
to 2018. The outcomes from the study disclosed that the nonrenewable impact on $\mathrm{CO}_{2}$ was positive, while the influence of renewable influence on $\mathrm{CO}_{2}$ was negative, suggesting that renewable energy helps in reducing degradation of the environment in the USA.

\subsection{Structural change influence on $\mathrm{CO}_{2}$}

According to the present framework for structural transformation, the secondary sector pollutes more than the tertiary sector; therefore, it enhances the quality of the environment (Grossman \& Krueger, 1991). According to this perspective, the current economic expansion processes are shifting from industry and agriculture to the service sector. This guarantees that the economy transitions from a highly ecologically hazardous (secondary and primary) state to one that is ecologically sustainable (tertiary). Furthermore, if the economy's income is low, individuals will migrate to the secondary sector, where wages are greater. In comparison with agriculture, the industrial sector produces pollution. People expect greater quality of the environment as their income rises; as a result, a shift toward the service sector may be seen (Ali et al., 2020). Similarly, it is argued that a shift from an emission-based to an information-based economy might, in the long term, ameliorate damage to the environment (Panayotou, 1997).

Various studies have reported this process of technological progress and structural change as a critical factor of traditional EKC realization (Shafik \& Bandyopadhyay, 1992; Villanthenkodath et al., 2021). From an empirical perspective, several studies have been conducted. For example, the research of Jayanthakumaran et al.(2012) on the structural change (SVD) and carbon emissions $\left(\mathrm{CO}_{2}\right)$ interrelationship in India unveiled that SVD mitigates $\mathrm{CO}_{2}$, while in China, SVD contributes to emission levels. Moreover, the research of Ali et al. (2020) on the SVD-CO $\mathrm{CO}_{2}$ association in Malaysia revealed a positive SVD-CO association. Furthermore, Alam and Adil (2019) scrutinized the structural change-emissions connection in India using advanced time-series approaches and their outcomes showed that SVD mitigates $\mathrm{CO}_{2}$ in India. Likewise, the study of Wang et al. (2020) established that an upsurge in structural change contributes to environmental sustainability. Additionally, the study of Ali et al. (2020) on the $\mathrm{SVD}-\mathrm{CO}_{2}$ nexus in higher-income countries demonstrated that structural change leads to a decrease in $\mathrm{CO}_{2}$. Moreover, the research of Huang et al. (2021) utilizing a dataset from 2000 to 2016 disclosed that both internal and external structural changes contribute to energy demand.

Numerous studies have examined the factors that influence the quality of environment in Turkey. Nevertheless, few studies in Turkey have included structural change as a determinant of environmental sustainability. As a result, the current paper not only investigates the long-run asymmetric impact of NREN, GDP and REN on $\mathrm{CO}_{2}$, but also considers the role of SVD. More specifically, the influence of structural change is examined to examine whether the service sector's value added can help Turkey reduce environmental deterioration.

\section{Theoretical framework}

Before constructing the empirical framework of $\mathrm{CO}_{2}$ emissions $\left(\mathrm{CO}_{2}\right)$, the current theoretical framework of the included variables is addressed. The factors that influence $\mathrm{CO} 2$ emissions have received significant attention in the environmental and energy economics literature. Energy use and economic expansion were considered the most important factors in the $\mathrm{CO}_{2}$ function in most studies (Ahmed \& Le, 2021; Akinsola et al., 2021; Udemba 
et al., 2021). The growth-emissions interrelationship can be classified into three components: Firstly, the scale effect phase where countries favor GDP growth and pay less attention to the sustainability of the environment. Countries in this stage are mostly low-income nations. The second phase is the composition effect phase where countries become aware of the cost of environmental degradation. This stage is also known as the turning point and industrial economies are observed to be in this stage. The last stage is the technical effect phase where nations move from industrial economies to service sector-based economies (Adebayo \& Rjoub, 2021; Kirikkaleli \& Adebayo, 2021; Solarin et al., 2018; Soylu et al., 2021). As a result, economic expansion was added as a factor in the $\mathrm{CO}_{2}$ function for Turkey in this research.

Nonrenewable energy utilization is another essential component in the $\mathrm{CO}_{2}$ function. It is anticipated that increasing the utilization of nonrenewable energy worsens the quality of the environment. The utilization of energy is considerably more essential in the $\mathrm{CO}_{2}$ function in an emerging nation like Turkey since the consumption of energy is a requirement for achieving a reasonable economic growth rate. To grasp their significance in influencing the quality of the environment in Turkey, this research utilizes renewable energy and structural change as additional drivers of $\mathrm{CO}_{2}$. The incorporation of structural change in the framework is based on the literature's assertion that service sector-led development is beneficial to environmental quality (Pata, 2021b).

Since nonrenewable energy use has exacerbated global warming, the international community is focusing on a sustainable development plan that calls for the adoption of green sources of energy (Ahmad et al., 2021). Renewable energy is an important component of cost-effective and technically possible GHG reduction solutions (Coelho et al., 2021). By lowering the dependence on fossil fuels, REN can aid in abating emission and maintaining energy security. The utilization of renewable energy sources may help to decrease energy prices, enhance quality of air and human health, and generate employment (Kihombo et al., 2021). Furthermore, the prices of energy imports can be lowered by utilizing local renewable energy resources such as wind, solar, biomass, geothermal energy, and hydropower (Sarkodie \& Strezov, 2018). Nations are moving to renewable energy for all these ecological reasons. Renewable energy is anticipated to overtake coal in power output by 2025 , and renewable sources will contribute $50 \%$ of the global production of electricity by 2050 (Cevik et al., 2021).

In an empirical context, the above theoretical framework enables us to assess the impacts of structural change, economic expansion, renewable energy and nonrenewable energy utilization on $\mathrm{CO}_{2}$ in Turkey. Therefore, the research function is illustrated as follows:

$$
C O_{2 t}=f\left(G D P_{t}, E C_{t}, R E N_{t}, S V D_{t}\right)
$$

where SVD, EC, $\mathrm{CO}_{2}$, and REN represent structural change, nonrenewable energy, $\mathrm{CO}_{2}$ emissions, economic expansion and renewable energy, respectively. Furthermore, in order to minimize skewness, the natural logarithm of the variables was taken.

\section{Data and methods}

\subsection{Data}

The necessary information on the variables of interest was initially gathered in order to achieve the goal of our investigation. Subsequently, the empirical framework was 



Fig. 2 Flow of analysis

Table 1 Data description

\begin{tabular}{lll}
\hline Variables & Symbol & Source \\
\hline $\mathrm{CO}_{2}$ Emissions & $\mathrm{CO}_{2}$ & $\mathrm{BP}$ \\
Structural change & $\mathrm{SVD}$ & WDI \\
Economic growth & $\mathrm{GDP}$ & WDI \\
Renewable energy consumption & $\mathrm{REN}$ & $\mathrm{BP}$ \\
Nonrenewable energy consumption & $\mathrm{NREC}$ & $\mathrm{BP}$ \\
\hline
\end{tabular}

constructed in this research based on the literature. The stated empirical model needs to be evaluated by utilizing a variety of advanced econometric methods to obtain credible results for policy development. As a result, the investigation began with an examination of the stationarity features of the gathered data. The investigation validated the nonlinearity of the variables of study after determining the order of integration of the indicators. In addition, the stated model's long-term connection was affirmed. Furthermore, we assessed the long- and short-run asymmetric influence of the independent variables on the dependent variables. This was followed by dynamic multiplier analysis and examination of the causal connection between $\mathrm{CO}_{2}$ and the regressors. The stages of the empirical analysis are presented in Fig. 2. Moreover, a description of the variables utilized in this empirical study is shown in Table 1.

\subsection{Model construction and methodology}

In this empirical analysis, we utilized the NARDL model to explore the asymmetric effect of structural change, economic growth, renewable and nonrenewable energy consumption on $\mathrm{CO}_{2}$ in Turkey. Equation 1 presents the research linear equation as follows:

$$
C O_{2 t}=\beta_{0}+\beta_{1} G D P_{t}+\beta_{2} N R E N_{t}+\beta_{3} R E N_{t}+\beta_{4} S V D_{t}+\varepsilon_{t}
$$

where $\mathrm{CO}_{2 \mathrm{t}}, \mathrm{GDP}_{\mathrm{t}}, \mathrm{NREN}_{\mathrm{T}}$, RENt and $\mathrm{SVD}_{\mathrm{t}}$ illustrate carbon emissions, economic growth, energy utilization, renewable energy utilization and structural change in Turkey. The association above carried out the linear interrelationship between the series of investigation, while the main study objective is to assess the nonlinear influence of structural change, economic growth, energy utilization and renewable energy consumption effect on $\mathrm{CO}_{2}$ emissions by utilizing the NARDL framework initiated by Shin et al. (2014). Since it takes into account different integration orders when estimating, this approach is highly versatile. It can be used without limiting the integration orders and is likewise appropriate for I (2). Furthermore, Granger and Yoon (2002) developed the notion of hidden cointegration, 
which defines cointegration interactions as the positive and negative components of independent variables.

$$
C O_{2 t}=f\left(G D P^{+}, G D P^{-}, N R E N^{+}, N R E N^{+}, R E N^{+}, R E N^{-}, S V D^{+}, S V D^{-}\right)
$$

The present research follows the study of Villanthenkodath et al. (2021) by assessing the nonlinear effect of structural change, economic growth, energies (renewable and nonrenewable energy consumption) effect on $\mathrm{CO}_{2}$ emissions and the research framework can be specified as follows:

$$
\begin{aligned}
C O_{2 t}= & \beta_{0}+\beta_{1} G D P^{+}+\beta_{2} G D P^{-}+\beta_{3} N R E N^{+}+\beta_{4} N R E N^{-}+\beta_{5} R E N^{+} \\
& +\beta_{6} R E N^{-}+\beta_{5} S V D^{+}+\beta_{6} S V D^{-}+\varepsilon_{t}
\end{aligned}
$$

The long-run effect of GDP, NREN, REN and SVD is depicted in Eq. 5 as depicted as follows:

$$
\begin{aligned}
\Delta C O_{2 t} & =\beta_{0}+\sum_{k=1}^{m} \beta_{1 k} \Delta C O_{2 t-k}+\sum_{k=1}^{m} \beta_{2 k} \Delta G D P_{t-k}+\sum_{k=1}^{m} \beta_{3 k} \Delta N R E N_{t-k} \\
& +\sum_{k=1}^{m} \beta_{4 k} \Delta R E N_{t-k}+\sum_{k=1}^{m} \beta_{5 k} \Delta S V D_{t-k}+\theta_{1} C O_{2 t-1}+\theta_{2} G D P_{t-1} \\
& +\theta_{3} N R E N_{t-1}+\theta_{4} \operatorname{REN}_{t-1}++\theta_{5} S V D_{t-1}+\varepsilon_{t}
\end{aligned}
$$

The error correction term (ECT) is stipulated by Eq. 5 which merged the short-run and long-run coefficients; the short-run coefficients are illustrated by variables with symbol $\Delta$, while the long-run variable coefficients are depicted with symbol $a_{t}=\theta^{+} b_{t}^{+}+\theta^{-} b_{t}^{-}$. Only the linear connection between the expected variables is described by Eq. (5). This model, nonetheless, can be transformed into a nonlinear cointegration equation. The regression is decomposed as $a_{t}=\theta^{+} b_{t}^{+}+\theta^{-} b_{t}^{-}+{ }_{t}$ where $\theta^{+} a n d \theta^{-}$are linked with coefficients in the long-term, whereas $b^{+} a n d b^{-}$are connected with coefficients in the short term and $b_{t}$ is a regressor which is disintegrated in Eq. 6 as follows:

$$
b_{t}=b_{t}^{+}+b_{t}^{-}
$$

where the regressors are illustrated by $b_{t}^{+} b_{t}^{-}$, which are divided into a partial sum of favorable and unfavorable shifts in Eqs. 7-12. Therefore both the negative and positive changes in GDP, NREN, REN and SVD are presented as follows:

$$
\begin{aligned}
& G D P^{+}=\sum_{i=1}^{t} \Delta G D P_{i}^{+}+\sum_{i=1}^{t} \max \left(\Delta G D P_{i,} O\right) \\
& G D P^{-}=\sum_{i=1}^{t} \Delta G D P_{i}^{-}+\sum_{i=1}^{t} \max \left(\Delta G D P_{i} O\right) \\
& N_{R E N^{+}}=\sum_{i=1}^{t} \Delta E C_{i}^{+}+\sum_{i=1}^{t} \max (\Delta N R E N O)
\end{aligned}
$$




$$
\begin{aligned}
N R E N^{-} & =\sum_{i=1}^{t} \Delta E C_{i}^{-}+\sum_{i=1}^{t} \max \left(\Delta \operatorname{NREN}_{i}, O\right) \\
R E N^{+} & =\sum_{i=1}^{t} \Delta R E N_{i}^{+}+\sum_{i=1}^{t} \max \left(\Delta R E N_{i}, O\right) \\
R E N^{-} & =\sum_{i=1}^{t} \Delta R E N_{i}^{-}+\sum_{i=1}^{t} \max \left(\Delta R E N_{i} O\right) \\
S V D^{+} & =\sum_{i=1}^{t} \Delta S V D_{i}^{+}+\sum_{i=1}^{t} \max \left(\Delta S V D_{i,} O\right) \\
S V D^{-} & =\sum_{i=1}^{t} \Delta S V D_{i}^{-}+\sum_{i=1}^{t} \max \left(\Delta S V D_{i} O\right)
\end{aligned}
$$

Subsequently, GDP, NREN, REN and SVD in Eq. 5 are replaced by $\mathrm{GDP}^{+} \mathrm{GDP}^{-}, \mathrm{NREN}^{+} \mathrm{NREN}^{-}, \mathrm{REN}^{+} \mathrm{REN}^{-}$and $\mathrm{SVD}^{+} \mathrm{SVD}^{-}$, respectively. Therefore, the NARDL is presented in Eq. 15 as follows:

$$
\begin{aligned}
\Delta C O_{2 t}= & \beta_{0}+\sum_{k=1}^{m} \beta_{1 k} \Delta C O_{2 t-k}+\sum_{k=1}^{m} \beta_{2 k} \Delta G D P_{t-k}^{+}+\sum_{k=1}^{m} \beta_{2 k} \Delta G D P_{t-k}^{-}+\sum_{k=1}^{m} \beta_{3 k} \Delta E C_{t-k}^{+} \\
& +\sum_{k=1}^{m} \beta_{3 k} \Delta E C_{t-k}^{-}+\sum_{k=1}^{m} \beta_{4 k} \Delta N R E N_{t-k}^{+}+\sum_{k=1}^{m} \beta_{4 k} \Delta N R E N_{t-k}^{-}+\sum_{k=1}^{m} \beta_{5 k} \Delta S V D_{t-k}^{+} \\
& +\sum_{k=1}^{m} \beta_{5 k} \Delta S V D_{t-k}^{-}+\theta_{1} C O_{2 t-1}+\theta_{2} G D P_{t-1}^{+}+\theta_{2} G D P_{t-1}^{-}+\theta_{3} N R E N_{t-1}^{+} \\
& +\theta_{3} N R E N_{t-1}^{-}+\theta_{4} R E N_{t-1}^{+}+\theta_{4} R E N_{t-1}^{-}+\theta_{5} D U M_{t}+\varepsilon_{t}
\end{aligned}
$$

In Eq. 15, long- and short-run coefficients for negative and positive shifts in the independent variables are depicted by $\beta_{\mathrm{k}}$ and $\theta_{\mathrm{k}}$, respectively. The connection between $\mathrm{CO}_{2}$ and NREN, GDP and REN in the long run is captured by the NARDL bounds test. If the F-statistics is more that the critical values (lower and upper), the null hypothesis of "no cointegration" will be dismissed.

In addition, the long-run asymmetric coefficients are calculated by employing favorable long-run coefficient $\left(L A_{i}=\beta(-) / \gamma\right)$ shifts. Equations $16-19$ illustrate the process for calculating multiplier effects with dynamic asymmetry.

$$
\begin{gathered}
A M G D P_{i(+)}=\sum_{k=0}^{i}\left(\frac{\delta C O_{2 i+k}}{\delta G D P_{i(+)}}\right), A M G D P_{i(-)}=\sum_{k=0}^{i}\left(\frac{\delta C O_{2 i+k}}{\delta G D P_{i(-)}}\right) \\
\operatorname{AMNREN~}_{i(+)}=\sum_{k=0}^{i}\left(\frac{\delta C O_{2 i+k}}{\delta N R E N_{i(+)}}\right), A M E C_{i(-)}=\sum_{k=0}^{i}\left(\frac{\delta C O_{2 i+k}}{\delta N R E N_{i(-)}}\right)
\end{gathered}
$$


Table 2 Descriptive statistics

\begin{tabular}{llllll}
\hline & $\mathrm{CO}_{2}$ & NREN & GDP & REN & SVD \\
\hline Mean & 0.417260 & 2.673848 & 3.853880 & -0.013238 & 1.673556 \\
Median & 0.463690 & 2.719655 & 3.838193 & 0.110697 & 1.696251 \\
Maximum & 0.719619 & 3.190540 & 4.181467 & 0.601168 & 1.757105 \\
Minimum & -0.053979 & 1.927734 & 3.551054 & -0.689540 & 1.480870 \\
Std. Dev & 0.216505 & 0.355436 & 0.176180 & 0.353704 & 0.071823 \\
Skewness & -0.425725 & -0.358922 & 0.284232 & -0.588505 & -1.158693 \\
Kurtosis & 2.084983 & 2.075980 & 2.037551 & 2.288993 & 3.279373 \\
Jarque-Bera & 3.580093 & 3.137554 & 2.863342 & 4.333273 & 12.48574 \\
Probability & 0.166952 & 0.208300 & 0.238909 & 0.114562 & 0.001944 \\
Observations & 55 & 55 & 55 & 55 & 55 \\
\hline
\end{tabular}

$$
\begin{aligned}
& \operatorname{AMREN}_{i(+)}=\sum_{k=0}^{i}\left(\frac{\delta C O_{2 i+k}}{\delta R E N_{i(+)}}\right), \operatorname{AMREN}_{i(-)}=\sum_{k=0}^{i}\left(\frac{\delta C O_{2 i+k}}{\delta R E N_{i(-)}}\right) \\
& \operatorname{AMSVD}_{i(+)}=\sum_{k=0}^{i}\left(\frac{\delta C O_{2 i+k}}{\delta S V D_{i(+)}}\right), A M S V D_{i(-)}=\sum_{k=0}^{i}\left(\frac{\delta C O_{2 i+k}}{\delta S V D_{i(-)}}\right)
\end{aligned}
$$

In Eqs. 16-19, $\mathrm{i}=0,1,2,3 \ldots$ and if $1 \rightarrow \infty$, then $\mathrm{AMi}(+) \rightarrow \operatorname{LAi}(+)$ and $\mathrm{AMi}(-) \rightarrow \mathrm{LAi}(-)$ are operative. We can identify the dynamic multiplier's influence owing to unfavorable and favorable changes in the specified variables owing to the asymmetric variances in $\mathrm{CO}_{2}$. As a result, if the discrepancies are large enough, these dynamic modifications may be useful in establishing a new equilibrium.

\section{Discussions of findings}

\subsection{Pre-estimation tests}

This section commences by presenting a description of the variables of study in Table 2 . The GDP mean is the highest, which ranges from 3.551054 to 4.181467 . This is followed by NREN (3.853880), which ranges from 3.468065 to 4.338912 , SVD (1.673556) which ranges from 1.480870 to $1.757105, \mathrm{CO}_{2}(0.417260)$ which ranges from -0.053979 to 0.719619 and REN (-0.013238) which ranges from -0.689540 to 0.601168 . The skewness values showed that $\mathrm{CO}_{2}$, NREN, REN and SVD are skewed negatively, whereas GDP is positively skewed. The kurtosis values revealed that CO2, EC, GDP and REN are platykurtic, while only SVD is leptokurtic. The Jarque Bera (P-value) indicated all series align, with the exception of SVD. Additionally, the RADAR chart (see Fig. 3) was utilized to illustrate the graphical outcomes of the data description.

It is vital to understand the variables' order of integration before further analyses are conducted. In doing so, the current research applied ADF and PP tests, which are known as conventional unit root tests. Table 3 shows the PP and ADF unit rot tests and the outcomes indicated that the variables of the study are I(1). Nevertheless, if there is a structural shift 



Fig. 3 RADAR Chart

Table 3 ADF and PP tests

\begin{tabular}{lllll}
\hline & Level & $\Delta$ & Level & $\Delta$ \\
\hline GDP & -2.1248 & -7.1973 & -2.2232 & -7.2033 \\
NREN & -2.9340 & -8.0941 & -2.9245 & -8.0981 \\
REN & -2.6777 & -8.0446 & -2.6777 & -8.5973 \\
SVD & -2.1311 & -8.6676 & -2.0415 & -8.6306 \\
$\mathrm{CO}_{2}$ & -2.3334 & -6.7267 & -2.3082 & -6.7327 \\
\hline
\end{tabular}

Depicts $P<0.01$

in the series, PP and ADF will produce unreliable outcomes. Time-series data are vulnerable to disruptions owing to structural and macroeconomic occurrences, such as regulations that may jeopardize the stability of the variables that characterize particular economic phenomena. Recessions, natural disasters as well as health problems such as COVID-19 and pandemics all have the potential to cause long-term economic shocks. These factors may have an impact on the outcomes of any study done in that nation. Such shocks are typically overlooked by conventional unit root tests, which compensate for them as stationary. Based on this understanding, we applied the Zivot-Andrews test developed by (Zivot \& Andrews, 2002) to simultaneously capture the stationarity characteristics and single breaks in series. The ZA outcomes are depicted in Table 4, which show that the variables are I(1) with GDP, EC, REN, SVD and $\mathrm{CO}_{2}$ having a single break in 1977, 1978, 1999, 1985 and 1981, respectively. Furthermore, it is vital to identify the nonlinearity of series before applying any econometric approach. Therefore, we utilized the BDS test proposed by Broock et al. (1996) and the outcomes are illustrated in Table 5. The outcomes show that all the variables of investigation are nonlinear; therefore, utilizing linear approaches like FMOLS, CCR, ARDL, DOLS, and VECM will produce misleading outcomes. 
Table 4 ZA unit root test

\begin{tabular}{llllll}
\hline & \multicolumn{2}{l}{ Level } & & & $\Delta$ \\
\cline { 2 - 3 } \cline { 5 - 6 } & T-stat & BD & & T-stat & BD \\
\hline GDP & -4.1888 & 1999 & & -5.5302 & 1977 \\
NREN & -3.6068 & 1999 & & -8.6079 & 1978 \\
REN & -4.6520 & 1975 & & -8.3135 & 1999 \\
SVD & -4.9368 & 1986 & & -9.2818 & 1985 \\
$\mathrm{CO}_{2}$ & -3.2582 & 1998 & & -7.1368 & 1981 \\
\hline
\end{tabular}

Depicts $P<0.01$

Table 5 BDS test

\begin{tabular}{llllll}
\hline & $\begin{array}{l}\mathrm{CO}_{2} \\
\text { Z-stat }\end{array}$ & $\begin{array}{l}\text { GDP } \\
\text { Z-stat }\end{array}$ & $\begin{array}{l}\text { SVD } \\
\text { Z-stat }\end{array}$ & $\begin{array}{l}\text { NREN } \\
\text { Z-stat }\end{array}$ & $\begin{array}{l}\text { REN } \\
\text { Z-stat }\end{array}$ \\
\hline M2 & $30.920^{*}$ & $28.513^{*}$ & $16.999^{*}$ & $29.801^{*}$ & $20.295^{*}$ \\
M3 & $32.499^{*}$ & $29.667^{*}$ & $18.299^{*}$ & $31.464^{*}$ & $21.590^{*}$ \\
M4 & 34.57 & $31.108^{*}$ & $19.726^{*}$ & $33.627^{*}$ & $23.195^{*}$ \\
M5 & $37.991^{*}$ & $34.105^{*}$ & $21.603^{*}$ & $36.954^{*}$ & $25.270^{*}$ \\
M6 & $42.839^{*}$ & $38.090^{*}$ & $24.134^{*}$ & $41.714^{*}$ & $28.142^{*}$ \\
\hline
\end{tabular}

*depicts $P<0.01$

\subsection{Cointegration result}

We proceed by assessing the interrelationship between $\mathrm{CO}_{2}$ and GDP, SVD, NREN and REN in the long run utilizing the NARDL bounds test. The outcomes of the NARDL bounds test are presented in Table 6. The F-statistics (12.704) is higher than the critical values (lower and upper). The bounds test present proof of a long-run interrelationship between $\mathrm{CO}_{2}$ and the regressors (SVD, GDP, EC and REN). Hence, the null hypothesis of "no cointegration" is dismissed.

\subsection{NARDL results}

The long-run asymmetric impact of GDP, REN, SVD and NREN on $\mathrm{CO}_{2}$ is presented in Table 7. The outcomes are as follows: positive changes in GDP have a positive influence on the $\mathrm{CO}_{2}$ level in Turkey. This simply demonstrates that holding other factors constant, a $1 \%$ upsurge in GDP causes the emissions level to increase by $0.2685 \%$. On the other hand, a negative shift in GDP does not have a significant effect on $\mathrm{CO}_{2}$ in Turkey. The asymmetric interrelationship between GDP and $\mathrm{CO}_{2}$ implies that Turkey may have compromised environmental sustainability in order to accomplish its long-term economic ambitions. This result relates to the basic problem of the growth-development tradeoff, which focuses on pertinent problems that include sustainable development (SDG-8) and access to energy (SDG-7). The dominant pro-growth attitude is reflected in Turkey, and this issue might be connected to the fact that the Turkish economy is driven by fossil fuels. According to the literature (Adebayo \& Acheampong, 2021; Gupta \& Goel, 2019), lowering national output may improve the sustainability of the 
Table 6 NARDL cointegration

\begin{tabular}{|c|c|c|}
\hline Estimated model & F-statistics & AIC Lags \\
\hline$\left(\begin{array}{l}\mathrm{CO}_{2} / \mathrm{GDP}^{+}, \mathrm{GDP}^{-}, \mathrm{NREN}^{+}, \mathrm{NREN}^{-}, \\
\mathrm{REN}^{+}, \mathrm{REN}^{-}, \mathrm{SVD}^{+}, \mathrm{SVD}^{-}, \mathrm{DUM}\end{array}\right)$ & $12.704 *$ & $(2,0,2,2,0,2,1,1,0,0)$ \\
\hline $1(0)$ & $1(1)$ & \\
\hline 1.88 & 2.99 & \\
\hline 2.14 & 3.3 & \\
\hline $2.5 \%$ & 3.6 & \\
\hline 2.65 & 3.97 & \\
\hline
\end{tabular}

*denotes $P<0.01$. Optimum lag length is based on AIC

Table 7 Short- and long-run NARDL results

\begin{tabular}{|c|c|c|c|c|c|c|c|c|}
\hline \multirow[b]{2}{*}{$\begin{array}{l}\text { Regres- } \\
\text { sors }\end{array}$} & \multicolumn{4}{|l|}{ Long-run } & \multicolumn{4}{|l|}{ Short-run } \\
\hline & Coefficient & Std. error & t-Statistic & $\begin{array}{l}\text { Prob- } \\
\text { ability }\end{array}$ & Coefficient & Std. error & $\begin{array}{l}\text { t-Statis- } \\
\text { tic }\end{array}$ & $\begin{array}{l}\text { Prob- } \\
\text { ability }\end{array}$ \\
\hline $\mathrm{NREN}^{+}$ & $0.9354 *$ & 0.1291 & 7.2425 & 0.0000 & $1.1281^{*}$ & 0.1284 & 8.7849 & 0.0000 \\
\hline $\mathrm{NREN}^{-}$ & $-0.4311^{* *}$ & 0.1872 & -2.3023 & 0.0280 & $0.4311^{*}$ & 0.1477 & 2.9180 & 0.0064 \\
\hline $\mathrm{GDP}^{+}$ & $0.2685 * * *$ & 0.1570 & 1.7097 & 0.0970 & $0.2685^{*}$ & 0.1129 & 2.3786 & 0.0235 \\
\hline $\mathrm{GDP}^{-}$ & 0.1726 & 0.2150 & 0.8027 & 0.4280 & $0.4410^{*}$ & 0.1201 & 1.6700 & 0.5009 \\
\hline $\mathrm{REN}^{+}$ & $-0.9104^{*}$ & 0.0284 & -4.2392 & 0.0002 & $-0.1204 *$ & 0.0601 & -5.9706 & 0.0000 \\
\hline $\mathrm{REN}^{-}$ & $-0.0497 *$ & 0.0342 & -4.3702 & 0.0001 & $-0.0391 * * *$ & 0.0202 & -1.9311 & 0.0624 \\
\hline $\mathrm{SVD}^{+}$ & $-0.3253^{*}$ & 0.1519 & -2.1409 & 0.0400 & -0.1139 & 0.0693 & $4.1185-$ & 0.0003 \\
\hline $\mathrm{SVD}^{-}$ & -0.1300 & 0.1473 & -5.8831 & 0.3838 & $-0.4804^{*}$ & 0.1166 & -1.6435 & 0.1101 \\
\hline DUM & 0.0124 & 0.0100 & 1.2389 & 0.2244 & - & - & - & - \\
\hline ECM & - & - & - & - & $-0.6788^{*}$ & 0.0845 & -8.7585 & 0.0000 \\
\hline $\mathrm{C}$ & -0.0609 & 0.0127 & -4.7949 & 0.000 & & & & \\
\hline \multicolumn{9}{|c|}{ Post-estimation tests } \\
\hline $\mathrm{R}^{2}$ & & \multicolumn{7}{|l|}{0.98} \\
\hline $\operatorname{Adj}^{2}$ & & \multicolumn{7}{|l|}{0.97} \\
\hline$\chi^{2} \mathrm{~J}-\mathrm{B}$ & & \multicolumn{7}{|c|}{$0.415[0.812]$} \\
\hline$\chi^{2} \mathrm{LM}$ & & \multicolumn{7}{|c|}{$0.582[0.564]$} \\
\hline$\chi^{2 \mathrm{ARCH}}$ & & \multicolumn{7}{|c|}{$0.053[0.818]$} \\
\hline$\chi^{2}$ RESET & & \multicolumn{7}{|c|}{$0.477[0.636]$} \\
\hline
\end{tabular}

*, ** and ** represent $P<0.01, P<0.05$ and $P<0.10$, respectively

environment; however, this approach is impractical since policy action should be capable of integrating adverse effects on the environment via economic expansion patterns. Based on these outcomes, this situation may raise concerns about reaching the SDG 13 targets, as the persistent economic expansion trajectory may place an obstacle in the way of accomplishing the climate action objective. The studies of Adebola Solarin et al. (2017) for India and China, Orhan et al. (2021) for India, Yuping et al. (2021) for Argentina and Akinsola et al. (2021) for Indonesia reported similar findings. 
Furthermore, positive shifts in structural change mitigate the level of $\mathrm{CO}_{2}$ emissions in Turkey. This illustrates that a $0.3253 \%$ decrease in the level of $\mathrm{CO}_{2}$ is attributed to a $1 \%$ upsurge in structural change when other factors are held constant. On the other hand, a negative shift in structural change does not have a significant influence on Turkey's emission levels. This study shows that the International Energy Agency's (IEA, 2021) reasoning regarding the influence of the tertiary sector on $\mathrm{CO}_{2}$ is correct in the Turkish context. The proffered rationale was that the service sector's value-added emissions are three times lower than emissions from the economy's industrial sector. It may be deduced that the change of economic structure mitigates degradation of the environment; that is, when the economy evolves from primary to secondary and secondary to tertiary sectors, $\mathrm{CO}_{2}$ emissions are reduced as people seek environmental quality rather than polluting the atmosphere. The most likely explanation for this observation is that economic structural changes may encourage innovation and investments. As a result, Turkey's economic efficiency has increased. Furthermore, the structural shift aids in the fight against climate change in Turkey, despite the absence of a comprehensive and realistic national climate strategy. As a result, if the economy is to expand sustainably, the economy's transition from a resource-depleting industrial sector to a nonresourceoriented services sector is critical. This finding concurs with the works of Jayanthakumaran et al. (2012) for China and Ali et al. (2020) for Pakistan.

While discussing Turkey's concerns about meeting the SDG-7 goals, the effects of directional nonrenewable energy consumption variations on $\mathrm{CO}_{2}$ must be discussed. Favorable shifts in nonrenewable energy influence $\mathrm{CO}_{2}$ positively in Turkey. This implies that a $0.9354 \%$ upsurge in $\mathrm{CO}_{2}$ is caused by a $1 \%$ upsurge in NREN when other factors are held constant. The probable reason for this is the expanding use of electricity as well as the utilization of crude oil and coal, which leads to increased $\mathrm{CO}_{2}$ (IEA, 2021). Moreover, owing to fast growth in manufacturing, transportation and industrialization systems in the post-liberalization era, Turkey's utilization of energy has expanded substantially, and this energy-led growth has progressively applied adverse impacts on the environment in the form of soaring emission levels. In addition, a negative variation in energy utilization mitigates $\mathrm{CO}_{2}$. Therefore, keeping other factors constant, a $0.4311 \%$ decrease in $\mathrm{CO}_{2}$ is caused by a $1 \%$ negative shift in energy utilization. This experience mirrors the situation in other emerging countries (Shahbaz et al., 2021). Aside from the scholarly literature, IRENA's (2019) research also addressed this problem for emerging countries. As a result, any policy action implemented in Turkey's economy to internalize this growing adverse environmental externality can be used as a model for other emerging nations with similar economic characteristics. While presenting the policy intervention, it should be recalled that the consumption of energy is also fueled by the unrelenting use of natural resources that might provide a significant impediment to achieving SDG 12. The debate in Turkey on energy-led growth requires cross-border resource mobility that has an influence on GDP and $\mathrm{CO}_{2}$ patterns via the energy utilization pathway. This finding is in accordance with the studies of Zhang et al. (2021) for Malaysia, Odugbesan et al. (2021) for Thailand and Alola et al. (2021) for China.

Finally, favorable (unfavorable) shifts in renewable energy utilization impact $\mathrm{CO}_{2}$ negatively. This suggests that $1 \%$ positive and negative shifts in REN mitigate $\mathrm{CO}_{2}$ by $0.9104 \%$ and $0.00497 \%$, respectively, in Turkey. The negative link is most probably due to the fact that renewable technology utilizes clean, green energy sources that can fulfill current and future demands while also reducing emissions. This conclusion makes sense from Turkey's standpoint since the country has launched a number of efforts to promote the utilization of 
renewable energy and mitigate the consumption of fossil fuel. Our research finding corroborates the studies of Yuping et al. (2021) for Argentina and Shan et al. (2021) for decentralized economies.

The outcomes of the short-run estimation are similar to the long-run outcomes. Furthermore, the ECT (-0.6788) coefficient is negative and statistically significant. This justifies the speed of adjustment and validates the cointegration. We applied several diagnostic tests to determine the credibility of the model. The $\mathrm{R}^{2}$ and adjusted $\mathrm{R}^{2}$ are 0.98 and 0.97 , which implies that a $98 \%$ of variation in $\mathrm{CO}_{2}$ can be explained by the regressors (NREN, SVD, REN and GDP), while the remaining $1 \%$ can be attributed to the error term. The outcomes from the diagnostic tests showed no evidence of serial correlation, and the residuals are normally distributed with no model misspecification and no heteroskedasticity. Furthermore, the CUSUM of square and CUSUM in Fig. 4a, b indicated that the model is stable.

The present research applied the WALD test to capture the long-run asymmetric significance of the series of the study. The outcomes from the test are illustrated in Table 8, and the outcomes disclosed that SVD, REN and EC have long-run asymmetries, while there is no proof of long-run asymmetries for GDP.

\subsection{Dynamic asymmetric multiplier outcomes}

The dynamic asymmetric multiplier's findings are shown in Fig. 5a, d, which shows the dynamic adjustment period between the parameters. Figure 5a, d illustrates the mechanism adjustment of $\mathrm{CO}_{2}$ with GDP, SVD, REN and NREN considering the lag length and favorable and unfavorable shifts. The difference and strength of asymmetric variations between favorable and unfavorable shifts are shown by the red-dotted lines, indicating that favorable and unfavorable fluctuations are statistically significant. We also contribute to the corpus of research on environmental sustainability in this way. Favorable and unfavorable changes are also represented by plain green and purple dotted lines, respectively. The positive-negative changes and time horizon are shown by the vertical and horizontal axes in Fig. 5a, d. In Fig. 5a, the favorable and unfavorable variations in REN are visible over time. Similarly, in Fig. 5b, favorable and unfavorable variations in energy utilization (NREN) are visible over time. Additionally, in Fig. 5c, favorable and unfavorable shifts in structural change (SVD) are noticeable over time. Lastly, in Fig. 5d, the favorable and unfavorable shifts in GDP are visible over time.

\subsection{Spectral causality outcomes}

The paper proceeds by assessing the causal influence of SVD, GDP, REN and NREN on $\mathrm{CO}_{2}$ in Turkey. In doing so, we applied the spectral causality test (SCT) ${ }^{1}$ proposed by (Breitung \& Candelon, 2006) to investigate the causal linkages between $\mathrm{CO}_{2}$ and the regressors (NREN, GDP, REN, and SVD). The benefit of the spectral causality test is that unlike conventional causality tests, the SCT can capture causation in series at various frequencies (short and long-term). The study outcomes revealed the following.

In the long term, there is proof of causation from structural change to $\mathrm{CO}_{2}$, which suggests that the null hypothesis of "no causality" is rejected at a significance level of $10 \%$. Nonetheless, in the short and medium term, there is no evidence to support causation from






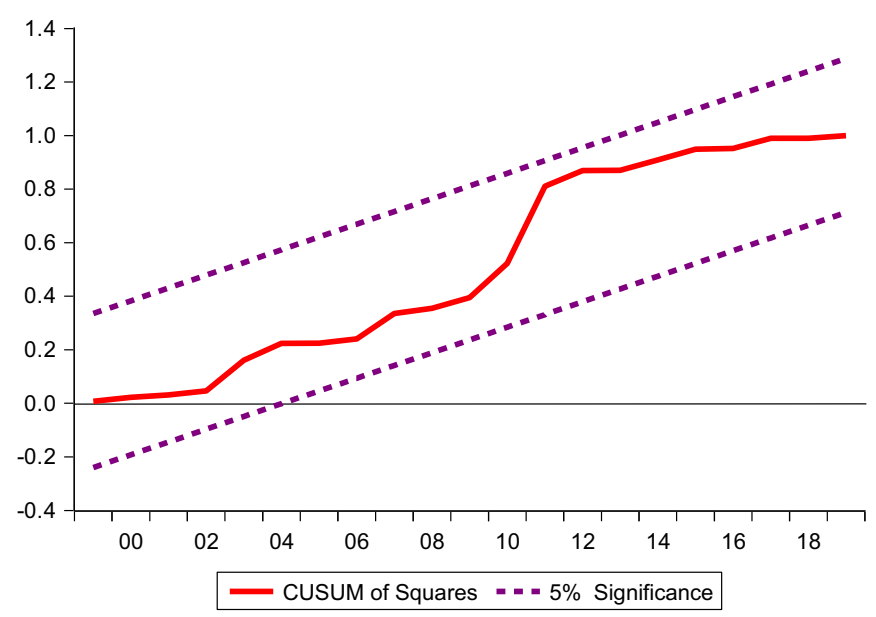

(a) CUSUM

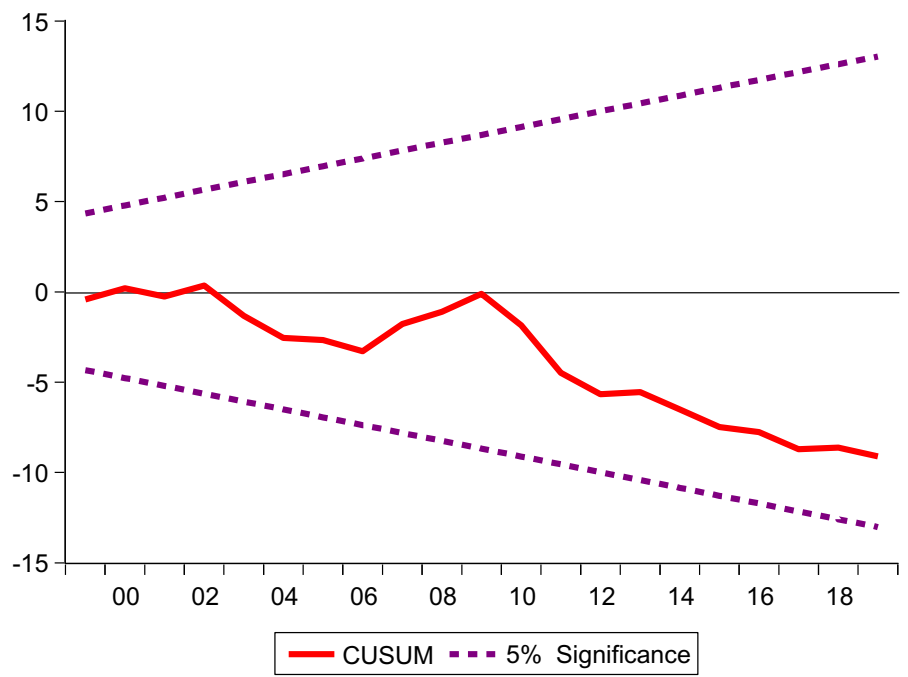

(b) CUSUM of Square

Fig. 4 a CUSUM, b CUSUM of square

Table 8 Long-run asymmetries (WALD) test

\begin{tabular}{llll}
\hline Variables & Chi-square & Probability & Decision \\
\hline GDP & 1.91223 & 0.1922 & No \\
NREN & $10.1761^{*}$ & 0.0000 & Yes \\
SVD & $5.43818^{*}$ & 0.0192 & Yes \\
REN & $16.2925^{*}$ & 0.0001 & Yes \\
\hline
\end{tabular}

*, ** and *** stand for $P<0.01, P<0.05$ and $P<0.10$, respectively 




(a) Multiplier for REN

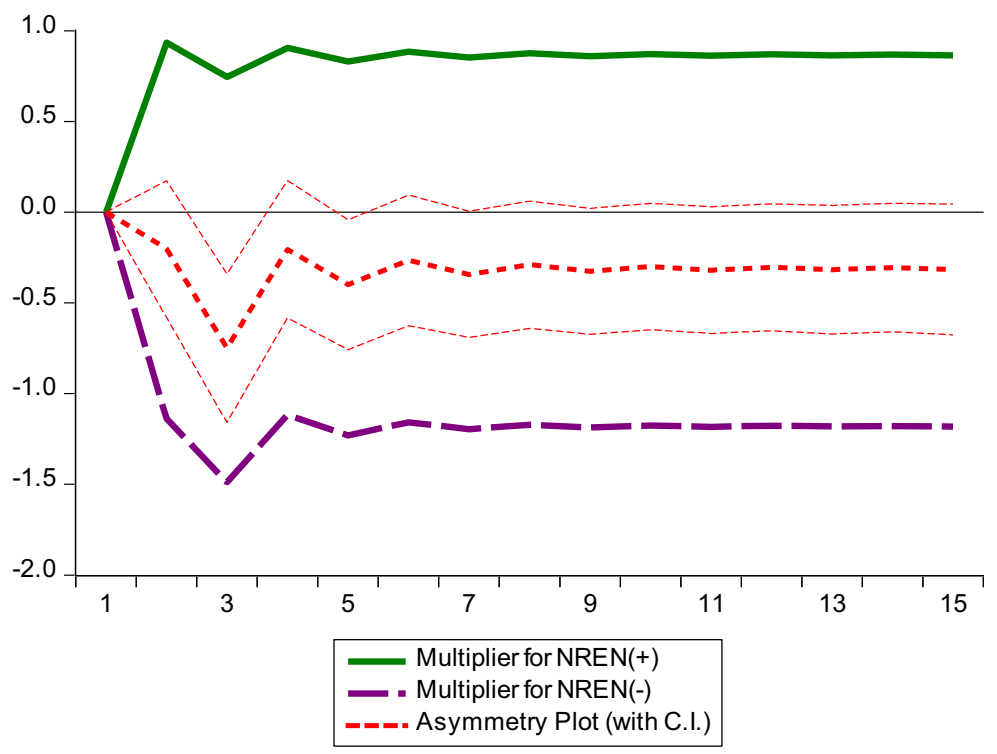

(b) Multiplier for NREN

Fig. 5 a Multiplier for REN, b multiplier for NREN, $\mathbf{c}$ multiplier for SVD, $\mathbf{d}$ multiplier for GDP

SVD to $\mathrm{CO}_{2}$, which illustrates that the null hypothesis of "no causality" cannot be rejected (see Fig. 6a). Moreover, at significance levels of 5\% and 10\%, respectively, GDP Granger causes $\mathrm{CO}_{2}$ in the long run. Thus, we fail to accept the null hypothesis of "no causality" (see Fig. 6b). 


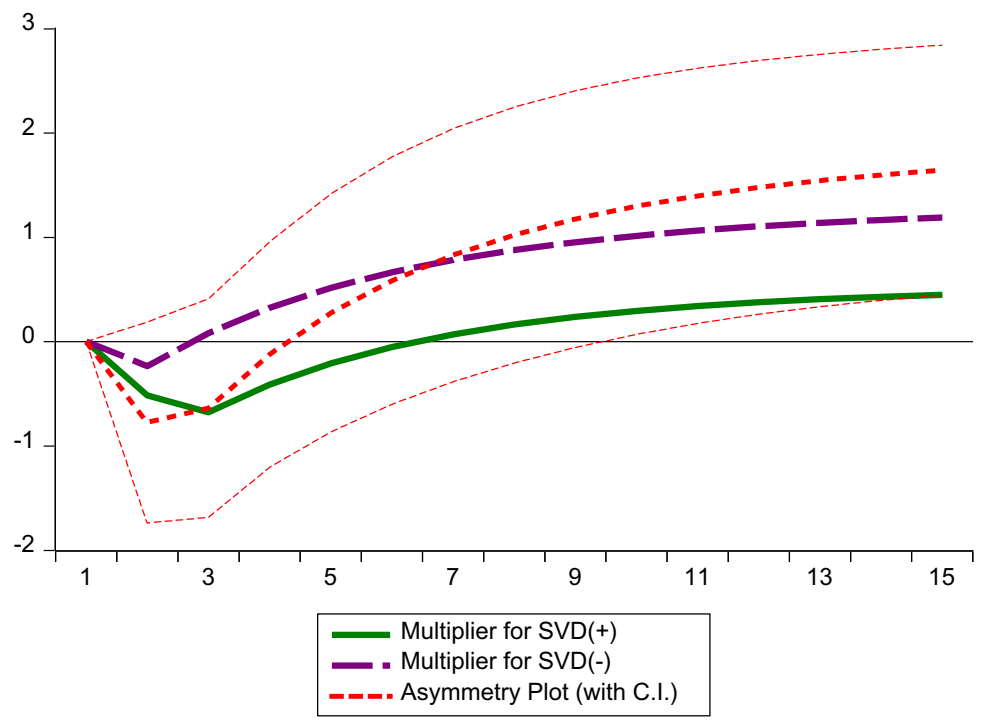

(c) Multiplier for SVD



(d) Multiplier for GDP

Fig. 5 (continued)

Furthermore, in the long term, there is no proof of causation from $\mathrm{REN}$ to $\mathrm{CO}_{2}$ in the long run; however, in the short and medium term, a Granger causality from REN to $\mathrm{CO}_{2}$ is affirmed at significance levels of $5 \%$ and $10 \%$, respectively. Hence, we fail to accept the null hypothesis of "no causality" in the short and medium term. respectively (see Fig. 6c). Lastly, there is no evidence to support the causal influence of energy utilization (NREN) on $\mathrm{CO}_{2}$ in the long term; however, in the medium and short term, we fail to reject proof 




(a) Spectral Causality from SVD to $\mathrm{CO}_{2}$



(b) Spectral Causality from GDP to $\mathrm{CO}_{2}$

Fig. 6 a Spectral causality from SVD to $\mathrm{CO}_{2}$, b Spectral causality from GDP to $\mathrm{CO}_{2}$, c Spectral causality from REN to $\mathrm{CO}_{2}$, d Spectral causality from NREN to $\mathrm{CO}_{2}$

of causation from NREN to $\mathrm{CO}_{2}$ at $5 \%$ and $10 \%$ levels of significance, respectively (see Fig. 6d).

The empirical outcomes from the SCT contribute to the ongoing studies on environmental sustainability. The findings from the research suggest that all the regressors (SVD, 


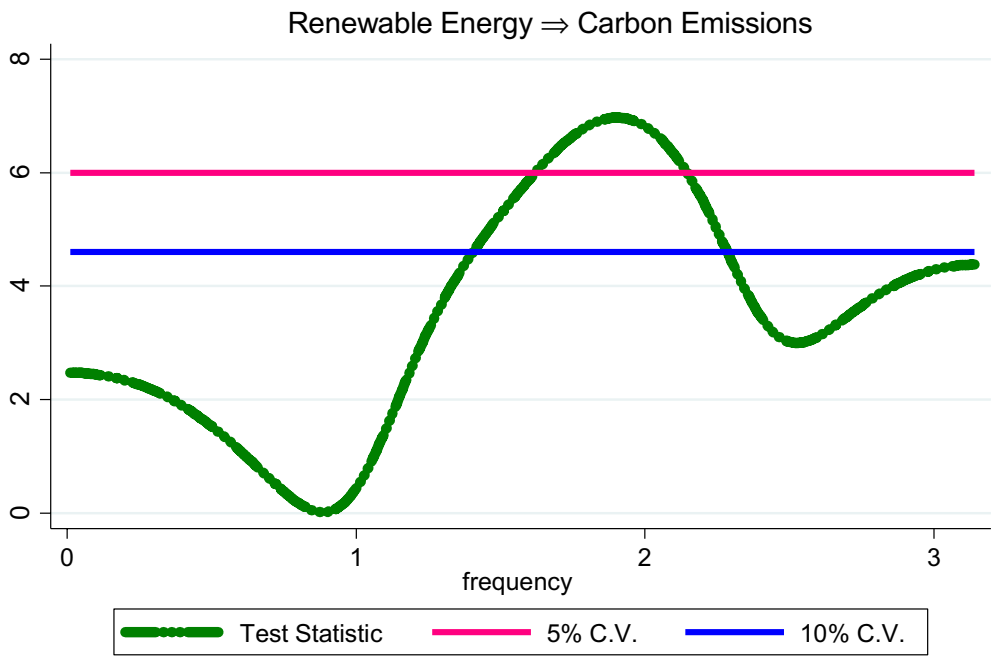

(c) Spectral Causality from REN to $\mathrm{CO}_{2}$



(d) Spectral Causality from NREN to $\mathrm{CO}_{2}$

Fig. 6 (continued)

GDP, NREN and REN) can predict $\mathrm{CO}_{2}$ at different frequencies (short and long term). These outcomes are interesting for policy makers in proposing policies on environmental sustainability in Turkey. Figure 7 presents a graphical illustration of the study. 




Fig. 7 Graphical illustration of study

\section{Conclusion and policy direction}

\subsection{Conclusion}

Prior environmental economics research has found that structural changes and renewable energy are important factors contributing to $\mathrm{CO}_{2}$ emissions. On the other hand, another group of studies suggests that structural changes and renewable energy enhance ecological quality by curbing $\mathrm{CO}_{2}$. In this light, the current research assessed the asymmetric influence of renewable energy use and structural change on $\mathrm{CO}_{2}$ emissions by controlling energy utilization and economic growth in the carbon emissions function in Turkey. The current research utilized yearly data spanning from 1965 to 2018 to scrutinize these associations. In doing so, we applied a series of econometric approaches such as PP, ADF, and ZA tests, and the BDS nonlinearity test to capture the series stationarity and nonlinearity characteristics. The outcomes from the stationarity and BDS tests showed that the indicators are I(1) and the variables are nonlinear, respectively. Based on this knowledge, utilizing linear approaches will produce misleading outcomes. Therefore, we used the NARDL approach suggested by Shin et al. (2014). Additionally, we applied the spectral causality test (SCT) to identify the causation between $\mathrm{CO}_{2}$ and the regressors at different frequencies. 
The NARDL bounds test outcome showed cointegration between $\mathrm{CO}_{2}$ and the regressors (GDP, NREN, REN and SVD). Furthermore, the NARDL long- and short-run outcomes disclosed that: (a) a positive shock in GDP triggers $\mathrm{CO}_{2}$, while negative shifts exert an insignificant influence on $\mathrm{CO}_{2}$; (b) positive (negative) shocks in renewable energy usage mitigate emission levels in Turkey; (c) favorable (unfavorable) changes in energy utilization increase (decrease) $\mathrm{CO}_{2}$ emissions; (d) a positive shock in structural change decreases $\mathrm{CO}_{2}$, while a negative shift in structural change does not exert a significant influence on $\mathrm{CO}_{2}$ in Turkey. Moreover, the outcomes from the spectral causality showed that in the long term, SVD and GDP can predict $\mathrm{CO}_{2}$, while REN and NREN can forecast $\mathrm{CO}_{2}$ in the medium and short term, respectively.

\subsection{Policy direction}

Based on the aforementioned empirical findings, the present research proposes the following policy suggestions. Firstly, a positive change in GDP contributes to degradation of the environment, while a negative shift in GDP does not contribute to environmental sustainability. This study suggests that per capita income in Turkey has not yet attained the required levels, which may motivate citizens to seek improved environmental quality. To address this issue to some extent, steps should be done to educate the public about the benefits and economic benefits of using renewable energy rather than nonrenewable energy.

Second, since favorable (unfavorable) shifts in nonrenewable energy increase (decrease) $\mathrm{CO}_{2}$ emissions, policies aimed at reducing fossil fuel usage must be adopted extensively in the face of worrisome climate change. In this regard, Turkey has to adopt a policy that encourages the use of renewable energy sources. Likewise, laws relating to the factors that increase energy usage must be controlled. It is also critical to adopt new technologies to improve energy efficiency, which will help to minimize $\mathrm{CO} 2$ by lowering the amount of energy needed to produce a given level of production. This type of energy efficiency enhancement initiative benefits both the environment and the economy; thus, energy efficiency measures in Turkey should be prioritized. Furthermore, household utilization of energy in the industrial and transportation sectors should be included in policy design. Energy-efficient energy gadgets are utilized at the household level to decrease the excessive utilization of energy. Subsidies for fossil fuels should also be phased out through strict rules at the state and central levels. Implementation of these strategies might help to minimize the climatic change that the study detected as a result of energy use.

Fourth, since favorable shifts in structural changes in Turkey reduce $\mathrm{CO}_{2}$, environmental sustainability can be enhanced by shifts in the economic structure. This implies that degradation of the environment can be decreased by emphasizing tertiary sector operations over secondary sector linked activities. As a result, we propose that Turkey's transition to service-sector-led growth will aid environmental protection. From a policy standpoint, we believe that service sector company subsidies, service sector-linked trade promotion efforts and international service sector collaboration should all be encouraged in Turkey. The service industry is an important part of any country's economy as it makes major and immediate contributions to employment creation and economic growth. Furthermore, the Turkish government must promote service sector growth; likewise, private and public sector engagement in service sector development is critical for future development. Aside from that, authorities should make developing a national action strategy for economic growth a priority with a focus on services-based activities. Furthermore, existing regulatory obstacles in the Turkish service sector must be eliminated in order to provide a challenging 
market for service sector businesses. By adopting the policies resulting from the structural change findings, the Turkish economy can achieve a higher level of environmental quality.

Lastly, since favorable (unfavorable) shifts in renewable energy mitigate environmental pollution, policymakers should encourage the adoption of renewable energy. Furthermore, businesses that engage in the production and assembly of alternative energy sources should be evaluated for incentives such as tax breaks and price controls. This will enable them to increase production, making items more affordable and accessible to both public and private interests.

\subsection{Limitation of study}

Despite the fact that this research gives important clues into the management of environmental sustainability in Turkey, one of the study's major shortcomings is the utilization of $\mathrm{CO}_{2}$ as a proxy for ecological degradation, which is a restricted measure of ecological degradation. Furthermore, because this research is limited to Turkey, the policies developed may not be relevant to neighboring nations. As a result, prolonging the analysis period and using other newly developed econometric methods to obtain more robust results is a viable future research direction. Furthermore, in future research, different proxies of environmental deterioration other than $\mathrm{CO}_{2}$ could be used. In addition, future research might include other nations in a time series or panel data collection to provide a more complete set of policy instruments.

\section{References}

Acheampong, A. O., Adams, S., \& Boateng, E. (2019). Do globalization and renewable energy contribute to carbon emissions mitigation in Sub-Saharan Africa? Science of the Total Environment, 677, 436-446. https://doi.org/10.1016/j.scitotenv.2019.04.353

Adebayo, T. S., \& Acheampong, A. O. (2021). Modelling the globalization-CO2 emission nexus in Australia: Evidence from quantile-on-quantile approach. Environmental Science and Pollution Research. https://doi.org/10.1007/s11356-021-16368-y

Adebayo, T. S., \& Kirikkaleli, D. (2021). Impact of renewable energy consumption, globalization, and technological innovation on environmental degradation in Japan: Application of wavelet tools. Environment, Development and Sustainability. https://doi.org/10.1007/s10668-021-01322-2

Adebayo, T. S., \& Rjoub, H. (2021). A new perspective into the impact of renewable and nonrenewable energy consumption on environmental degradation in Argentina: A time-frequency analysis. Environmental Science and Pollution Research. https://doi.org/10.1007/s11356-021-16897-6

Adebola Solarin, S., Al-Mulali, U., \& Ozturk, I. (2017). Validating the environmental Kuznets curve hypothesis in India and China: The role of hydroelectricity consumption. Renewable and Sustainable Energy Reviews, 80, 1578-1587. https://doi.org/10.1016/j.rser.2017.07.028

Adedoyin, F. F., Ozturk, I., Agboola, M. O., Agboola, P. O., \& Bekun, F. V. (2021). The implications of renewable and non-renewable energy generating in Sub-Saharan Africa: The role of economic policy uncertainties. Energy Policy, 150, 112115. https://doi.org/10.1016/j.enpol.2020.112115

Agyekum, E. B., Kumar, N. M., Mehmood, U., Panjwani, M. K., Haes Alhelou, H., Adebayo, T. S., \& Al-Hinai, A. (2021). Decarbonize Russia-A Best-Worst Method approach for assessing the renewable energy potentials, opportunities and challenges. Energy Reports, 7, 4498-4515. https://doi.org/10. 1016/j.egyr.2021.07.039

Ahmad, M., Ahmed, Z., Majeed, A., \& Huang, B. (2021). An environmental impact assessment of economic complexity and energy consumption: Does institutional quality make a difference? Environmental Impact Assessment Review, 89, 106603. https://doi.org/10.1016/j.eiar.2021.106603

Ahmed, Z., \& Le, H. P. (2021). Linking Information Communication Technology, trade globalization index, and $\mathrm{CO} 2$ emissions: Evidence from advanced panel techniques. Environmental Science and Pollution Research, 28(7), 8770-8781. https://doi.org/10.1007/s11356-020-11205-0 
Akadırı, S. S., Alola, A. A., \& Usman, O. (2021). Energy mix outlook and the EKC hypothesis in BRICS countries: A perspective of economic freedom vs. economic growth. Environmental Science and Pollution Research, 28(7), 8922-8926. https://doi.org/10.1007/s11356-020-11964-w

Akinsola, G. D., Adebayo, T. S., Kirikkaleli, D., Bekun, F. V., Umarbeyli, S., \& Osemeahon, O. S. (2021). Economic performance of Indonesia amidst $\mathrm{CO} 2$ emissions and agriculture: A time series analysis. Environmental Science and Pollution Research. https://doi.org/10.1007/s11356-021-13992-6

Alam, R., \& Adil, M. H. (2019). Validating the environmental Kuznets curve in India: ARDL bounds testing framework. OPEC Energy Review, 43(3), 277-300. https://doi.org/10.1111/opec.12156

Ali, W., Rahman, I. U., Zahid, M., Khan, M. A., \& Kumail, T. (2020). Do technology and structural changes favour environment in Malaysia: An ARDL-based evidence for environmental Kuznets curve. Environment, Development and Sustainability, 22(8), 7927-7950. https://doi.org/10.1007/s10668-019-00554-7

Alola, A. A., Adebayo, T. S., \& Onifade, S. (2021). Examining the dynamics of ecological footprint in China with spectral Granger causality and Quantile-on-Quantile approaches. International Journal of Sustainable Development \&amp; World Ecology. https://doi.org/10.1080/13504509.2021.1990158

Bashir, M. F., Ma, B., Shahbaz, M., Shahzad, U., \& Vo, X. V. (2021). Unveiling the heterogeneous impacts of environmental taxes on energy consumption and energy intensity: Empirical evidence from OECD countries. Energy, 226, 120366. https://doi.org/10.1016/j.energy.2021.120366

Breitung, J., \& Candelon, B. (2006). Testing for short- and long-run causality: A frequency-domain approach. Journal of Econometrics, 132(2), 363-378. https://doi.org/10.1016/j.jeconom.2005.02.004

Broock, W. A., Scheinkman, J. A., Dechert, W. D., \& LeBaron, B. (1996). A test for independence based on the correlation dimension. Econometric Reviews, 15(3), 197-235. https://doi.org/10.1080/0747493960 8800353

Cevik, E. I., Yıldırım, D. Ç., \& Dibooglu, S. (2021). Renewable and non-renewable energy consumption and economic growth in the US: A Markov-Switching VAR analysis. Energy and Environment, 32(3), 519-541. https://doi.org/10.1177/0958305X20944035

Cheng, C.-Y., Chien, M.-S., \& Lee, C.-C. (2021). ICT diffusion, financial development, and economic growth: An international cross-country analysis. Economic Modelling, 94, 662-671. https://doi.org/10. 1016/j.econmod.2020.02.008

Coelho, M. F., Adebayo, T. S., Onbaşıŏlu, D. Ç., Rjoub, H., Mata, M. N., Carvalho, P. V., Rita, J. X., \& Adeshola, I. (2021). Modeling the dynamic linkage between renewable energy consumption, globalization, and environmental degradation in South Korea: does technological innovation matter? Energies, 14(14), 4265. https://doi.org/10.3390/en14144265

Farooq, M. U., Shahzad, U., Sarwar, S., \& ZaiJun, L. (2019). The impact of carbon emission and forest activities on health outcomes: Empirical evidence from China. Environmental Science and Pollution Research, 26(13), 12894-12906. https://doi.org/10.1007/s11356-019-04779-x

Fatima, T., Shahzad, U., \& Cui, L. (2021). Renewable and nonrenewable energy consumption, trade and $\mathrm{CO} 2$ emissions in high emitter countries: Does the income level matter? Journal of Environmental Planning and Management, 64(7), 1227-1251. https://doi.org/10.1080/09640568.2020.1816532

Fu, Q., Álvarez-Otero, S., Sial, M. S., Comite, U., Zheng, P., Samad, S., \& Oláh, J. (2021). Impact of renewable energy on economic growth and $\mathrm{CO} 2$ emissions-evidence from BRICS countries. Processes, 9(8), 1281. https://doi.org/10.3390/pr9081281

Grossman, G. M., \& Krueger, A. B. (1991). Environmental Impacts of a North American Free Trade Agreement. In Papers (No. 158; Papers). Princeton, Woodrow Wilson School - Public and International Affairs. https://ideas.repec.org/p/fth/priwpu/158.html

Gupta, V., \& Goel, R. (2019). Managing dissolved methane gas in anaerobic effluents using microbial resource management-based strategies. Bioresource Technology, 289, 121601. https://doi.org/10. 1016/j.biortech.2019.121601

Huang, J., Zhang, H., Peng, W., \& Hu, C. (2021). Impact of energy technology and structural change on energy demand in China. Science of the Total Environment, 760, 143345. https://doi.org/10.1016/j. scitotenv.2020.143345

IEA. (2021). International Energy Association. https://www.iea.org/countries/sweden.

Jayanthakumaran, K., Verma, R., \& Liu, Y. (2012). CO2 emissions, energy consumption, trade and income: A comparative analysis of China and India. Energy Policy, 42, 450-460. https://doi.org/10.1016/j. enpol.2011.12.010

Kihombo, S., Ahmed, Z., Chen, S., Adebayo, T. S., \& Kirikkaleli, D. (2021). Linking financial development, economic growth, and ecological footprint: What is the role of technological innovation? Environmental Science and Pollution Research. https://doi.org/10.1007/s11356-021-14993-1

Kirikkaleli, D., \& Adebayo, T. S. (2020). Do renewable energy consumption and financial development matter for environmental sustainability? New global evidence. Sustainable Development. https://doi. org/10.1002/sd.2159 
Kirikkaleli, D., \& Adebayo, T. S. (2021). Do public-private partnerships in energy and renewable energy consumption matter for consumption-based carbon dioxide emissions in India? Environmental Science and Pollution Research, 28(23), 30139-30152. https://doi.org/10.1007/s11356-021-12692-5

Kirikkaleli, D., Adebayo, T. S., Khan, Z., \& Ali, S. (2021). Does globalization matter for ecological footprint in Turkey? Evidence from dual adjustment approach. Environmental Science and Pollution Research, 28(11), 14009-14017. https://doi.org/10.1007/s11356-020-11654-7

Kirikkaleli, D., \& Kalmaz, D. B. (2020). Testing the moderating role of urbanization on the environmental Kuznets curve: Empirical evidence from an emerging market. Environmental Science and Pollution Research, 27(30), 38169-38180. https://doi.org/10.1007/s11356-020-09870-2

Luukkanen, J., Panula-Ontto, J., Vehmas, J., Liyong, L., Kaivo-oja, J., Häyhä, L., \& Auffermann, B. (2015). Structural change in Chinese economy: Impacts on energy use and CO2 emissions in the period 2013-2030. Technological Forecasting and Social Change, 94, 303-317. https://doi.org/10. 1016/j.techfore.2014.10.016

Mahalik, M. K., Mallick, H., \& Padhan, H. (2021). Do educational levels influence the environmental quality? The role of renewable and non-renewable energy demand in selected BRICS countries with a new policy perspective. Renewable Energy, 164, 419-432. https://doi.org/10.1016/j.renene. 2020.09.090

Meadows, D. L., Behrens, W. W., Meadows, D. H., Naill, R. F., Randers, J., \& Zahn, E. (1974). The anatomical basis of prosopagnosia. Journal of Neurology, Neurosurgery \& Psychiatry, 37(5), 489-501.

Odugbesan, J. A., Adebayo, T. S., Akinsola, G. D., \& Olanrewaju, V. O. (2021). Determinants of environmental degradation in Thailand: empirical evidence from ARDL and wavelet coherence approaches. Pollution, 7(1), 181-196. https://doi.org/10.22059/poll.2020.309083.885

Orhan, A., Adebayo, T. S., Genç, S. Y., \& Kirikkaleli, D. (2021). Investigating the linkage between economic growth and environmental sustainability in India: do agriculture and trade openness matter? Sustainability, 13(9), 4753. https://doi.org/10.3390/su13094753

Panayotou, T. (1997). Demystifying the environmental Kuznets curve: Turning a black box into a policy tool. Environment and Development Economics, 2(4), 465-484. https://doi.org/10.1017/S1355 770X97000259

Pata, U. K. (2021a). Renewable and non-renewable energy consumption, economic complexity, CO2 emissions, and ecological footprint in the USA: Testing the EKC hypothesis with a structural break. Environmental Science and Pollution Research, 28(1), 846-861. https://doi.org/10.1007/ s11356-020-10446-3

Pata, U. K. (2021b). Linking renewable energy, globalization, agriculture, CO2 emissions and ecological footprint in BRIC countries: A sustainability perspective. Renewable Energy, 173, 197-208. https://doi.org/10.1016/j.renene.2021.03.125

Rjoub, H., Akinsola, G. D., Oladipupo, S. D., \& Adebayo, T. S. (2021). The asymmetric effects of renewable energy consumption and trade openness on carbon emissions in Sweden: New evidence from quantile-on-quantile regression approach. Environmental Science and Pollution Research. https://doi.org/10.1007/s11356-021-15706-4

Sarkodie, S. A., \& Adams, S. (2018). Renewable energy, nuclear energy, and environmental pollution: Accounting for political institutional quality in South Africa. Science of the Total Environment, 643, 1590-1601. https://doi.org/10.1016/j.scitotenv.2018.06.320

Sarkodie, S. A., \& Strezov, V. (2018). Empirical study of the environmental Kuznets curve and environmental sustainability curve hypothesis for Australia, China, Ghana and USA. Journal of Cleaner Production, 201, 98-110. https://doi.org/10.1016/j.jclepro.2018.08.039

Shafik, N., \& Bandyopadhyay, S. (1992). Economic Growth and Environmental Quality: Time-series and Cross-country Evidence. World Bank Publications.

Shahbaz, M., Sharma, R., Sinha, A., \& Jiao, Z. (2021). Analyzing nonlinear impact of economic growth drivers on CO2 emissions: Designing an SDG framework for India. Energy Policy, 148, 111965. https://doi.org/10.1016/j.enpol.2020.111965

Shahzad, U. (2020). Environmental taxes, energy consumption, and environmental quality: Theoretical survey with policy implications. Environmental Science and Pollution Research, 27(20), 2484824862. https://doi.org/10.1007/s11356-020-08349-4

Shan, S., Ahmad, M., Tan, Z., Adebayo, T. S., Man Li, R. Y., \& Kirikkaleli, D. (2021). The role of energy prices and non-linear fiscal decentralization in limiting carbon emissions: Tracking environmental sustainability. Energy, 234, 121243. https://doi.org/10.1016/j.energy.2021.121243

Sharif, A., Baris-Tuzemen, O., Uzuner, G., Ozturk, I., \& Sinha, A. (2020). Revisiting the role of renewable and non-renewable energy consumption on Turkey's ecological footprint: Evidence from Quantile ARDL approach. Sustainable Cities and Society, 57, 102138. https://doi.org/10.1016/j.scs. 2020.102138 
Shin, Y., Yu, B., \& Greenwood-Nimmo, M. (2014). Modelling Asymmetric Cointegration and Dynamic Multipliers in a Nonlinear ARDL Framework. In R. C. Sickles \& W. C. Horrace (Eds.), Festschrift in Honor of Peter Schmidt: Econometric Methods and Applications (pp. 281-314). New York: Springer. https://doi.org/10.1007/978-1-4899-8008-3_9

Solarin, S. A., Al-Mulali, U., Gan, G. G. G., \& Shahbaz, M. (2018). The impact of biomass energy consumption on pollution: Evidence from 80 developed and developing countries. Environmental Science and Pollution Research, 25(23), 22641-22657. https://doi.org/10.1007/s11356-018-2392-5

Soylu, Ö. B., Adebayo, T. S., \& Kirikkaleli, D. (2021). The Imperativeness of environmental quality in china amidst renewable energy consumption and trade openness. Sustainability, 13(9), 5054. https:// doi.org/10.3390/su13095054

Su, Z.-W., Umar, M., Kirikkaleli, D., \& Adebayo, T. S. (2021). Role of political risk to achieve carbon neutrality: Evidence from Brazil. Journal of Environmental Management, 298, 113463. https://doi.org/10. 1016/j.jenvman.2021.113463

Tufail, M., Song, L., Adebayo, T. S., Kirikkaleli, D., \& Khan, S. (2021). Do fiscal decentralization and natural resources rent curb carbon emissions? Evidence from developed countries. Environmental Science and Pollution Research. https://doi.org/10.1007/s11356-021-13865-y

Udemba, E. N., Adebayo, T. S., Ahmed, Z., \& Kirikkaleli, D. (2021). Determinants of consumption-based carbon emissions in Chile: An application of non-linear ARDL. Environmental Science and Pollution Research. https://doi.org/10.1007/s11356-021-13830-9

Usman, O., Akadiri, S. S., \& Adeshola, I. (2020). Role of renewable energy and globalization on ecological footprint in the USA: Implications for environmental sustainability. Environmental Science Pollution Research, 27(24), 30681-30693.

Villanthenkodath, M. A., Ansari, M. A., Shahbaz, M., \& Vo, X. V. (2021). Do tourism development and structural change promote environmental quality? Evidence from India. Environment, Development and Sustainability. https://doi.org/10.1007/s10668-021-01654-Z

Wang, Z., Rasool, Y., Zhang, B., Ahmed, Z., \& Wang, B. (2020). Dynamic linkage among industrialisation, urbanisation, and $\mathrm{CO} 2$ emissions in APEC realms: Evidence based on DSUR estimation. Structural Change and Economic Dynamics, 52, 382-389. https://doi.org/10.1016/j.strueco.2019.12.001

Yuping, L., Ramzan, M., Xincheng, L., Murshed, M., Awosusi, A. A., Bah, S. I., \& Adebayo, T. S. (2021). Determinants of carbon emissions in Argentina: The roles of renewable energy consumption and globalization. Energy Reports, 7, 4747-4760. https://doi.org/10.1016/j.egyr.2021.07.065

Zhang, L., Li, Z., Kirikkaleli, D., Adebayo, T. S., Adeshola, I., \& Akinsola, G. D. (2021). Modeling CO2 emissions in Malaysia: An application of Maki cointegration and wavelet coherence tests. Environmental Science and Pollution Research, 28(20), 26030-26044. https://doi.org/10.1007/ s11356-021-12430-X

Zivot, E., \& Andrews, D. W. K. (2002). Further evidence on the great crash, the oil-price shock, and the unit-root hypothesis. Journal of Business \&amp; Economic Statistics, 20(1), 25-44. https://doi.org/10. $1198 / 073500102753410372$

Publisher's Note Springer Nature remains neutral with regard to jurisdictional claims in published maps and institutional affiliations.

\section{Authors and Affiliations}

\section{Tomiwa Sunday Adebayo ${ }^{1}\left[\right.$ ] Seun Damola Oladipupo ${ }^{2} \cdot$ Husam Rjoub $^{3} \cdot$ Dervis Kirikkaleli ${ }^{4}$ (I) Ibrahim Adeshola ${ }^{5}$}

Tomiwa Sunday Adebayo

twaikline@gmail.com

Seun Damola Oladipupo

seunlad50@gmail.com

Husam Rjoub

hrjoub@ciu.edu.tr

Dervis Kirikkaleli

dkirikkaleli@eul.edu.tr 
Ibrahim Adeshola

deshyengr@live.com

1 Department of Business Administration, Faculty of Economics and Administrative Science, Cyprus International University, 99040 Nicosia, Turkey

2 Faculty of Earth Science, Department of Science, Olabisi Onabanjo University, Ogun State, Nigeria

3 Department of Accounting and Finance, Faculty of Economics and Administrative Sciences, Cyprus International University, Mersin 10, 99040 Haspolat, Turkey

4 Faculty of Economic and Administrative Sciences, Department of Banking and Finance, European University of Lefke, Lefke, Northern Cyprus, TR-10 Mersin, Turkey

5 Department of Information Technology, School of Computing and Technology, Eastern Mediterranean University, North Cyprus, 10, Mersin, Turkey 